\title{
Entre norma e decisão: o ensaio sobre o Valor do Estado do jovem Carl Schmitt
}

\author{
Between norm and decision: the essay on the Value of the State by the young \\ Carl Schmitt
}

Walter Andrade*

\section{Resumo}

O presente artigo discute o ensaio O valor do Estado e a significação do indivíduo (Der Wert des Staates und die Bedeutung des Einzelnen) (1914) de Carl Schmitt. Pouco abordado pela bibliografia voltada a Schmitt até o momento, mesmo em países onde a obra do autor tem sido largamente debatida, este livro, pretende-se revelar aqui, encerraria, em germe, certos aspectos fundamentais de uma epistemologia jurídica de tipo decisionista, que o autor viria a desenvolver e consolidar anos mais tarde, notadamente em sua Teologia política (1922). Assim, é certo, esse trabalho, anterior à eclosão da I Guerra Mundial, deve muito, do ponto de vista metodológico, a Kant ou à vertente neokantiana em filosofia do direito - um fato curioso, aliás, considerando os caminhos futuros tomados pela reflexão do autor. Sua elaboração da relação entre direito e ética, tanto quanto a do problema da decisão, em certas passagens, porém, parece ir de encontro à perspectiva "evolucionista" e "normativista" que essa tradição, de uma forma ou de outra, sempre representou. No mais, insiste-se aqui, diversos são os temas que despontam nessa primeira incursão do autor pelo terreno da filosofia política, os quais, mais tarde, figurarão em sua produção intelectual mais conhecida, a partir dos anos 20, conectando-se lá, certamente, a um quadro epistemológico novo. É o caso, por exemplo, de uma "antropologia negativa", ou de certa beligerância, ao menos tendencial, que se associaria, de maneira indelével, à própria condição humana etc. Diante de todas essas temáticas, importantes para uma compreensão interna da trajetória intelectual de Schmitt e presentes neste trabalho, torna-se injustificada a pouca atenção que, até o momento, tem-Ihe sido dispensada.

Palavras-chave: Carl Schmitt. O valor do Estado e a significação do indivíduo. Decisionismo. Immanuel Kant. Neokantismo.

\section{Abstract}

The present article discusses the essay The value of the State and the significance of the individual (Der Wert des Staates und die Bedeutung des Einzelnen) (1914), by Carl Schmitt. Uncommonly approached by the literature concerned with Schmitt until now, even in countries where the author's work has been widely debated, this book, I wish to reveal here, would contain in it, in embryo, some fundamental aspects of a legal epistemology of a decisionist kind, which the author would develop and consolidate years later, namely in his Political theology (1922). Thus, certainly, this work, prior to the outbreak of World War l, owes much, from the methodological point of view, to Kant or to the Neo-Kantian trend in philosophy of law - a curious fact, by the way, considering the future paths taken by the author's reflection -. Its elaboration of the relation between law and ethics, as much as of the problem of decision, however, in certain passages, seems to go against the "evolutionary", and "normativist" perspective, which this tradition, in one way or another, has normally represented. Furthermore, I insist here, there are many subjects that emerge in this first incursion of the author on the field of political philosophy that, later, will figure in his most well-known intellectual production, from the twenties on, connecting there, of course, to a new epistemological framework. This is the case, for example, of a "negative anthropology", or of a certain, at least tendential, belligerency, which would associate, in an indelible manner, to human condition itself, etc. In face of all those subjects, important to an inner comprehension of Schmitt's intellectual trajectory, which are present in this work, the little attention that so far is being provided to it turns out to be unjustified.

Keywords: Carl Schmitt. The value of the State and the significance of the individual. Decisionism. Immanuel Kant. NeoKantianism.

\footnotetext{
Doutor e mestre em Direito pela Faculdade de Direito da Universidade de São Paulo. Pós-doutorando em Sociologia na Faculdade de Filosofia, Letras e Ciências Humanas da USP. Professor de Filosofia do Direito e Direito Constitucional na Universidade de Santo Amaro. São Paulo - SP - Brasil. E-mail: walterppandrade@gmail.com.
} 


\section{Introdução}

O presente artigo se debruça sobre um trabalho, em grande medida, negligenciado na bibliografia schmittiana, mesmo em países onde se desenvolve consideravelmente: trata-se do ensaio sobre $O$ valor do Estado e a significação do indivíduo (Der Wert des Staates und die Bedeutung des Einzelnen), de 1914, que constituiu a tese de habilitação do autor (SCHMITT, 2003). Qual poderia ser o interesse desse trabalho, já centenário, para o debate schmittiano dos nossos dias? Mais: qual seria o seu interesse para as discussões contemporâneas em filosofia do direito e filosofia política? Pretende-se demonstrar com este breve artigo, em primeiro lugar, que o ensaio sobre $O$ valor do Estado, apesar de apresentar-se, em princípio, como uma compreensão tipicamente normativista do fenômeno jurídico - o que, por si só, chama a atenção por se tratar de um autor que, mais tarde, notabilizar-se-ia por suas teses "decisionistas", ou "institucionalistas", avessas a qualquer redução da teoria do direito ao problema da norma - na verdade, testemunha o enraizamento profundo do problema de uma "decisão soberana" - indiferente, do ponto de vista de seu conteúdo pelo menos, a toda determinação normativa, no espírito do autor. A epistemologia jurídica decisionista, que o autor mais tarde sistematizou e consolidou em obras como Teologia política (1922) - que se atrela, de forma emblemática, ao problema do estado de exceção ${ }^{1}$-, despontaria, em germe, já em $O$ valor do Estado - com outras temáticas importantes para a produção schmittiana posterior -, particularmente na ênfase que se dispensa aqui à noção de uma decisão virtualmente incondicionada do ponto de vista normativo (ou socioestrutural), característica que seria da práxis jurídica em seus diversos níveis e segmentos.

Frequentemente, assimila-se o pensamento schmittiano dos anos 20 e início dos anos 30 a uma cientificidade jurídica de tipo "decisionista". A essa orientação inicial sobrepor-se-ia, em meados dos anos 30, uma nova, de tipo "institucionalista", mais ou menos coincidente com a adesão do autor à política do nacional-socialismo. No pós-45, finalmente, o problema da decisão tornaria a ganhar vulto no pensamento de Schmitt, mas aqueles motivos oriundos dessa epistemologia institucionalista, apoiada em autores como Hauriou ou Santi Romano, não viriam a desaparecer completamente. ${ }^{2}$

De um ângulo diverso, Julien Freund argumentava, já na década de 70, que o pensamento schmittiano dos anos 20 deveria ser encarado como uma espécie de articulação dos paradigmas decisionista e institucionalista, e não como uma pura manifestação do primeiro, ao qual, apenas mais tarde, viria a acrescentar-se, e sobrepor-se, o segundo (Freund, 1978). Trata-se de um debate em que tomaram parte autores brasileiros. ${ }^{3}$ Se a obra schmittiana dos anos 20 não constitui, especificamente, o objeto do presente artigo, fato é que, na década anterior, enquanto nada parecia apontar para a "virada institucionalista" dos anos 30 , o problema de uma decisão normativamente incondicionada, articulada a uma série de motivos que permearão a produção schmittiana posterior, desempenhava já, como se pretende demonstrar, um papel fundamental na tese de habilitação do autor, prenunciando para muitos a argumentação (decisionista) das obras Ditadura (1921) e Teologia política (1922).

Demais disso, pretende-se, ainda, revelar neste artigo a importância - em alguns momentos, bem entendido, negativa - que a vertente neokantiana em filosofia do direito e mesmo a filosofia jurídica de Kant assumem para o argumento do ensaio de 1914, notadamente naquilo que respeita ao tema dessa decisão virtualmente desembaraçada de qualquer critério normativo. Nesse sentido, indica-se, a seguir, que o decisionismo jurídico schmittiano se revelaria, em boa medida, desde seu momento seminal, e principalmente aí, uma resposta às abordagens tipicamente normativistas da temática jurídica, oferecidas pelos teóricos da vertente neokantiana, que gozava ainda de grande prestígio intelectual, e mesmo pelo próprio Kant, a

Com efeito, a episteme jurídica definia-se, ali, a partir da oposição polar entre norma e decisão. Assim, se, "no caso normal, o momento autônomo da decisão pode ser repelido a um mínimo", tem-se que "no caso excepcional", justamente aquele da decisão sobre a exceção, "a norma é aniquilada" (SCHMITT, 2006, p. 13). Para a apresentação da concepção schmittiana da soberania nessa obra, em sua conexão com o conceito de uma decisão extrema, e, nesse sentido, com o problema do estado de exceção, cf., particularmente, caps. 1 e 3 (SCHMITT, 2006 , p. 7-15 e p. 35-48).

Cf., a esse respeito, Kervégan (1992, p. 38 e p. 39-48).

Cf. Macedo Jr. (2001); e Bercovici (2002). 
quem se dirige o jovem Schmitt, nessa brochura de 1914, em certas passagens fundamentais. ${ }^{4}$ Poderia o pensamento jurídico dos nossos dias, referenciado que se mostra em tantos motivos característicos da filosofia política e jurídica de Kant, encontrar inspiração para a solução de seus dilemas nessas críticas do jovem Carl Schmitt ao filósofo da Aufklärung?

\section{Kant e Kelsen: referências do Ensaio de 1914}

Esse trabalho, que antecede a eclosão da Primeira Guerra Mundial em alguns meses, apresenta um Schmitt com algo insólito. O leitor habituado às teses da primazia da força ou da ordem concreta sobre a norma, que normalmente se associam ao autor, surpreende-se com a exposição obstinada de um Schmitt normativista. $^{5}$

Com efeito, para o jovem autor desse ensaio, "o direito", logicamente, "precede o Estado". ${ }^{6}$ A atmosfera neokantiana, típica do momento histórico em que emerge a obra sob análise, e diretamente o próprio pensamento de Kant, parecem, em princípio, influenciar decisivamente as teses metodológicas desse trabalho. ${ }^{7}$ Assim, a propósito da discussão de uma vontade objetiva que fundamentaria a atuação estatal e legiferante, Schmitt nos remete ao pensamento de Kant como meio de compreender essa instância fundamental em termos normativos, e essencialmente não empíricos. ${ }^{8}$ Em outro passo, abordando a questão dos fins ou objetivos do direito posto pelo Estado, a formulação kelseniana da temática é elogiada pelo autor. ${ }^{9}$ Com Kelsen, aliás, em outro momento, afirma que todo Estado é um Estado de direito. ${ }^{10} \mathrm{Em}$

\footnotetext{
Também aqui, curiosamente, parecem convergir os interesses teóricos dos jovens Carl Schmitt e Walter Benjamin. O tema foi explorado em minha tese de doutorado, da qual se extrai a maior parte deste artigo. Cf. Andrade (2017). Assim, as reflexões do primeiro sobre o tema da "decisão" neste livro de 1914, bem como as do segundo num ensaio de 1921, a Crítica da violência, sobre o tema da "indecidibilidade" que afetaria, em última análise, todo o horizonte da práxis jurídica, dando base, respectivamente, às formulações ulteriores de ambos sobre o tema do estado de exceção, teriam como referência negativa, justamente, o normativismo característico das concepções jusfilosóficas de matriz kantiana ou neokantiana, hegemônicas à época. Cf. Andrade (2017, p. 40-52 e p. 93-106). Se, mais tarde, esses autores se lerão e citarão, recíproca e polemicamente, a propósito dos temas da soberania, da decisão e da exceção, o campo de problemas em que se dá essa discussão parece ser determinado, em parte, por esses seus dois trabalhos de juventude (ANDRADE, 2017, p. 52-92, 106-137, e 141-153)

5 O quadro, como se sabe, é bastante diverso durante o período de Weimar: cf. Kervégan (1992, p. 38): "[...] Auctoritas, non veritas facit legem. [...] o emblema da orientação decisionista que ele adota"; e "[...] a oposição entre esses dois tipos [normativismo e decisionismo] tem para Schmitt o alcance de uma distinção epistemológica, e mesmo metafísica, capital para a teoria do direito. Ela se encontra também, sob diversas espécies, em todas as suas obras que datam dos anos 1920" (p. 39). Todas as passagens de livros estrangeiros citadas neste artigo foram traduzidas livremente para o português pelo autor.

6 "O direito precede o Estado" (SCHMITT, 2003, p. 66).

"Em O valor do Estado e a significação do indivíduo, é essencialmente a razão que constitui a primeira fonte de legitimação do direito. A insistência de Carl Schmitt sobre o recurso à razão, - necessário à legitimação do direito e do Estado -, o acento posto sobre a importância de uma argumentação racional, desprovida de todo elemento empírico, assim como sua definição do sujeito autônomo como ser de razão, com evidentes ecos kantianos, dão à razão um estatuto proeminente no conjunto de sua demonstração. [...]. Em O valor do Estado e a significação do indivíduo, a fonte de validade do direito, assim como a do Estado, reside na razão e não no que releva do factual (konkret-faktisch). [...] Em contrapartida, o direito, que, em O valor do Estado e a significação do indivíduo, é primeiro, quase absoluto, perderá seu estatuto proeminente, para se deixar determinar pelo político, na realidade o Estado, tal como aparece na Teologia política e na Teoria da Constituição. Essa transição sublinha a mudança mais considerável que se tenha operado entre a redação de $O$ valor do Estado e a significação do indivíduo e os textos subsequentes. [...]. Em O valor do Estado e a significação do indivíduo, são Immanuel Kant e Hans Kelsen - teóricos do Estado de direito - que constituem seus referenciais intelectuais, que serão, desde 1922, na Teologia política, eliminados ou violentamente criticados". (BAUME, 2003, p. 47-48; 50-51). A autora, porém, na sequência, atenua essa afirmação de descontinuidade na evolução das ideias de Schmitt, remetendo às temáticas da decisão e do Estado. Ressaltando a proximidade deste ensaio de 1914 a Kelsen e ao neokantismo, cf. ainda Solon (1997), p. 103. Em sentido semelhante, e chamando a atenção para o elemento dualista da abordagem schmittiana, Paulson (2016, p. 512-513): "Na monografia O Valor do Estado (1914), Schmitt defende uma posição dualista em teoria do direito. O dualismo se reflete nas justaposições familiares, por exemplo, de Sein e Sollen, fato e valor, realidade e Ideia (Wirklichkeit und Idee), tal como são entendidas no trabalho de neokantianos fin-de-siècle, cuja posição é manifesta nos argumentos que aduziam contra a miríade de teorias
} psicológicas e naturalistas do momento".

8 "[...]. A fim de elucidar essa concepção [retomada a seguir], pode-se referir-se à analogia do primado kantiano da razão prática ou da primazia da vontade sobre o intelecto [...]. No entanto, essa opinião bem difundida entre os juristas, que considera que a vontade da lei deve ser o critério da interpretação, opor-se-ia vigorosamente a essa analogia, se de uma outra maneira a vontade, da qual emana o direito - enquanto sentido 'racional', 'conteúdo de pensamento objetivo', vontade 'verdadeira', ou pouco importa a maneira como se a nomeará - pode ser oposta a uma vontade simplesmente factual dos autores da lei. Por essa única e possível concepção da interpretação, que se opõe à vontade, qual um simples fato, o direito como norma tem uma posição que é análoga àquela do juiz independente. [...]. É assim possível e pensável que a 'vontade do Estado' seja igualmente submetida a uma apreciação que associe à 'lei' um elemento que seja superior ao caráter factual de um querer poderoso" (SCHMITT, 2003, p. 99-100).

9 "A questão relativa ao lugar do conceito de finalidade, que merece uma pesquisa específica, atingiu, graças aos trabalhos importantes e meritórios de Kelsen, uma nova fase de interesse científico" (SCHMITT, 2003, p. 118).

10 "[...] não há outro Estado que o Estado de direito [...]" (SCHMITT, 2003, p. 101). Esclarecendo essa passagem, afirma-se, logo acima: "O conceito de 'Estado de direito' remete ao primado do direito, ele se refere ao Estado numa perspectiva de filosofia do direito. O Estado é normado pelo direito: o segundo corresponde a um princípio de validade anterior ao primeiro. Os elementos constitutivos do conceito de Estado só podem ser emprestados ao direito, uma vez que a qualificação de Estado de direito não remete a uma conjunção contingente de relações factuais de um Estado empírico com um complexo de normas jurídicas, mas significa a reunião do Estado e do direito, sendo o primeiro totalmente compreendido e determinado pelo segundo. O Estado é inteiramente elevado à esfera do direito" (SCHMITT, 2003, p. 99). 
suma, na esteira de Kant e do espírito filosófico de sua época, compreende-se aqui o Estado e todas as relações empíricas, factuais, dizentes com o jurídico, como absorvidos, em última instância, pela esfera da norma, âmbito de origem, pressuposto lógico fundamental de todo conhecimento jurídico: "Assim o primado do direito é fundado. O poder puramente factual jamais pode remontar a um qualquer fundamento, sem pressupor uma norma, pela qual esse fundamento se legitima" (SCHMITT, 2003, p. 97). ${ }^{11}$

A prioridade epistemológica da norma abstrata sobre o concreto e empírico é, pois, afirmada inequivocamente:

O direito, concebido como a única entidade pura, de valor, em que os fatos não justificam as normas, posiciona-se logicamente como o primeiro elo da corrente. O Estado liga em seguida esse universo do pensamento ao mundo real e empírico [...]. Entretanto, o indivíduo, como ser empírico, desaparece para ser compreendido pelo direito e pelo Estado. Este último desempenha seu papel de mediador do direito, a fim de tirar sua significação dessa tarefa e seu valor desse mundo fechado, regido por suas próprias normas. [...] (SCHMITT, 2003, p. 62). ${ }^{12}$

\section{Direito e sanção: divergências em relação a Kelsen e Kant}

Sem embargo, o acordo do autor com Kant ou Kelsen na obra, baseando-se no primado do normativo sobre o fático, e, por essa via, do direito sobre o Estado, é menor do que se supõe à primeira vista. Logo intervém o tema da sanção, e as divergências em relação ao jurista austríaco, que fazia desta um elemento intrínseco à norma jurídica, evidenciam-se:

[...] o caráter jurídico de uma norma não tem nada a ver com a coercibilidade ou com uma propensão a esta. A coerção e a propensão a ela se referem ao mundo empírico real, ao ser, elas têm em vista um estado concreto da realidade, cuja realização por meios reais constitui seu objetivo. Como esse objetivo que aspira a ser atingido é essencialmente estranho ao direito, enquanto norma, então a tendência à coerção não se origina do direito, mas do Estado, que constitui um meio para uso do direito. [...]. A coerção ou a coercibilidade não concernem à essência da norma, elas relevam da coação, é dizer, aquilo que pela via de coerção é tornado conforme à norma. Por consequência, elas não podem ser o sinal distintivo da norma jurídica em relação a outros complexos normativos (SCHMITT, 2003, p. 103). ${ }^{13}$

O problema da coerção é fundamental, também, para a crítica do autor à noção kantiana de dever jurídico, a qual se havia atrelado a ideia de um móbil patológico, basicamente a sanção. Nesse contexto, Schmitt impugna, em seu próprio estatuto lógico, a determinação do conceito de dever jurídico apresentada por Kant (SCHMITT, 2003, p. 103-104). Radicalizando, em certo sentido, a dicotomia kantiana entre a esfera da norma e a esfera do fato, avança o autor que a coerção só poderia aparecer como pertencente à segunda,

11 Eis a passagem completa da qual se extraiu o trecho acima: "O poder supremo que engendra o Estado é, por sua essência, uma unidade que se estabelece unicamente por critérios de valor. [...]. O direito não está no Estado, é o Estado que está no direito. "Assim o primado do direito é fundado. O poder puramente factual jamais pode remontar a um qualquer fundamento, sem pressupor uma norma, pela qual esse fundamento se legitima. Para o poder que é apenas factual, há apenas casos concretos, expressões pontuais de um poder cego e sem continuidade, e não uma vontade que se forma em uma unidade racional" (SCHMITT, 2003, p. 97).

12 Mais adiante, no mesmo sentido, lê-se: "O Estado se encontra no centro dessa tripartição. O lugar do Estado como mediador entre dois universos resulta de uma oposição entre a norma e o mundo real empírico. Nesse ponto cardinal, o direito passa do pensamento puro a um fenômeno terrestre. O Estado é portanto uma formação da esfera jurídica, cujo sentido reside exclusivamente na tarefa de realizar o direito. Com efeito, trata-se de provocar um estado do mundo exterior que corresponda, na medida do possível, às exigências oriundas das reflexões jurídicas, que se referem ao comportamento dos indivíduos e à organização do mundo exterior" (SCHMITT, 2003, p. 100-101). Categoricamente exposta e sistematizada neste trabalho, tal orientação normativista terá, porém, em Schmitt, vida curta. Ela parecia insinuar-se já, é certo, em fins de 1912. Assim, em dezembro daquele ano, anotações no diário do jovem autor avançavam: "É um grande erro acreditar que direito = poder", para concluir, em última análise, que "O direito deve existir antes do mundo e existir depois dele" (SCHMITT, 2003, p. 60 apud BENDERSKY, 2016, p. 123). Essa tendência "neoidealista" manifesta-se ainda, chama-nos a atenção Paulson (2016, p. 517-518) numa resenha crítica escrita pelo autor em 1916, tendo por objeto um trabalho, ele próprio, de orientação neokantiana, de Julius Binder, Rechtsbegriff und Rechtsidee. A partir desse mesmo ano, porém, novos temas, e uma orientação metodológica voltada, cada vez mais, para o nível do concreto e efetivo, prepararão o terreno para Ditadura, de 1921, e Teologia política, de 1922, em seu aspecto e método francamente decisionistas.

13 Cf., no mesmo sentido, Schmitt (2003, p. 112). 
jamais à primeira. ${ }^{14} \mathrm{Em}$ se acolhendo, porém, a coerção como um elemento constitutivo da norma jurídica, como faz Kant, seria necessário, argumenta Schmitt, expor o nexo necessário entre aquela e esta forma de legalidade externa - a prioridade da coerção sobre outros móbeis patológicos na definição kantiana do dever jurídico resultaria meramente contigente, arbitrária, não fundada filosoficamente. ${ }^{15}$ Ademais, se 0 móbil patológico, particularmente a coerção, é apontado como elemento distintivo do dever jurídico, seria igualmente necessário esclarecer a ideia de uma coerção fundada, diversa das demais formas de coerção, meramente fáticas, que podem sobrevir - o que, segundo Schmitt, não é feito. ${ }^{16}$

\title{
4 Direito e ética: as críticas a Kant e aos neokantianos
}

\author{
As críticas de Schmitt a Kant neste trabalho, porém, não se limitam ao problema da relação entre \\ direito e coerção.
}

Um aspecto crucial dessa obra para uma pesquisa interessada em reconstruir a formação da epistemologia decisionista de Schmitt reside na crítica que nela se endereça à articulação entre o direito e a ética estabelecida pela filosofia prática de Kant. Esta, com efeito, supunha uma filosofia da história que avocava uma aproximação progressiva, mesmo infinita, do concreto ao abstrato, das instituições jurídicas concretamente existentes ao seu fundamento ideal, abstrato, ancorado na ética. ${ }^{17}$ É essa aproximação

14 “...] então a autoridade de um dever jurídico pode muito bem residir também na razão. O elemento da coerção surge porém como um acaso. Se a coerção se torna essencial - e é o caso em Kant, porque ele daí deduz que o dever jurídico só pode ser uma ação exterior - então a coerção deve resultar da essência mesma do dever jurídico, o que significa que um dever jurídico é um dever que, segundo sua essência, incita à coerção. Mas essa incitação ou essa propensão tenderia ao empírico, àquilo que é conforme à experiência, uma vez que a coerção só se refere ao mundo exterior e empírico. A coerção só poderia resultar do conteúdo empírico, concreto de uma norma. Entretanto, utilizar esse conteúdo empírico para caracterizar uma norma jurídica pode também ser considerado como um dos erros mais grosseiros e mais funestos. Se o direito pertence a esse tipo de normas - cujo conceito está em discussão e que não pode ser conhecido pela experiência - então o postulado da pureza se realiza e cada relação com a coerção desaparece. Toda propensão à coercibilidade se torna acidental e uma tal correlação, acessória. A coerção e a coercibilidade só podem ser conhecidas pela experiência, a propensão à coerção só pode ter como essência a experiência e não uma norma pura" (SCHMITT, 2003, p. 105).

15 Essa prioridade se assentaria antes na observação empírica da práxis jurídica que num desenvolvimento imanente do sistema da filosofia do direito do autor: "Ademais, não é evidente que o móbil que, como se diz, constitui uma forma de dever deva estar contido justamente em uma coerção, e não em um efeito totalmente diferente sobre a vontade. Kant passa ao largo disso e afirma: [...]. Se é igualmente evidente para nós que na prática empírica do direito se trabalha com medidas de coerção e não com recompensas e incitações, essa evidência, em todo caso para Kant, não constitui ainda um argumento; ela não resulta do sistema de filosofia do direito kantiano, ela provém do exterior e serve a elidir uma dificuldade importante" (SCHMITT, 2003, p. 106).

16 "Além disso, a definição que concebe o direito pelo seu oposto, a ética, segundo a distinção kantiana, não resolve as questões mais importantes, em particular aquelas que se relacionam ao fundamento da coerção jurídica. [...]. Ninguém pode coagir quem quer que seja à execução de seus deveres e não pode conferir assim aos deveres, que seriam de outro modo éticos, um caráter jurídico: se o nobre salteador coage um homem rico a ajudar um terceiro com fome, a ação do rico não resulta de um dever jurídico. Só uma coerção fundada confere ao dever uma natureza jurídica, o acento é posto sobre o fundamento, não sobre a coerção. Por sua vez, esse fundamento não pode ser explicado por uma referência à coerção, uma vez que ele cessaria assim de corresponder a uma norma e seria o resultado de relações factuais. [...]" (SCHMITT, 2003, p. 105-106).

17 O tema é discutido em Andrade (2017, p. 13-39). Nos Princípios Metafísicos da Doutrina do Direito, define-se a liberdade como o único "direito inato". (Cf.: KANT, s./d., p. 44). "Kant obtém o 'princípio universal do direito' aplicando o princípio moral a relações 'externas'. [...]" (HABERMAS, 1997, p. 100). A ideia de uma lei universal da liberdade nos compele, pois, ao respeito pelo objeto exterior de cada um, o que só é possível pelo abandono do estado de natureza e pelo ingresso em um estado civil: "se deve ser juridicamente possível ter um objeto exterior como seu, então permitir-se-á também ao sujeito forçar qualquer um, com quem entre em conflito sobre o meu e o teu acerca de semelhante objeto, a ingressar com ele numa constituição civil" (KANT, s./d., p. 64); "[...] Portanto, a primeira coisa que o homem está obrigado a decidir, se não quiser renunciar a todos os conceitos jurídicos, é o princípio: é necessário sair do estado de natureza em que cada um age conforme o seu desejo, e associar-se a todos os outros (com os quais não pode evitar entrar em interacção) para se submeter a uma coerção externa publicamente legal, portanto, entrar num estado em que a cada um se determina legalmente e se atribui, mediante um poder suficiente (que não é o seu, mas exterior), o que deve ser reconhecido como o seu; ou seja, deve, antes de tudo, entrar num estado civil" (KANT, s./d., p. 126-127). A passagem para o estado civil, por sua vez, opera-se mediante um "contrato originário", que, porém, não se toma como um fato histórico, empírico, mas, antes, como uma ideia reguladora da razão: "O acto pelo qual o próprio povo se constitui como Estado - em rigor só a ideia deste, que é a única pela qual se pode pensar a sua legitimidade - é o contrato originário, segundo o qual todos (omnes et singuli) no povo renunciam à sua liberdade exterior para, em seguida, a recuperar como membros de uma comunidade, isto é, como membros do povo considerado como Estado (universi); e não se pode dizer que o Estado, o homem no Estado, tenha sacrificado a um fim uma parte da sua liberdade exterior inata, mas abandonou por completo a sua liberdade selvagem e sem lei, para de novo encontrar a sua liberdade em geral, íntegra, na dependência legal, a saber, num estado jurídico; porque esta dependência brota da sua própria vontade legisladora" (KANT, s./d., p. 130). Tomado como um ponto de partida, em sentido transcendental, de toda comunidade política, apresenta-se o contrato originário, igualmente, como telos, como ponto de chegada necessário de toda ordem político-jurídica empiricamente existente. Cabe à humanidade, e particularmente ao soberano, trabalhar, infinitamente, por uma aproximação progressiva, tão rápida quanto possível, das instituições políticas concretamente existentes à ideia de uma constituição republicana, que se desdobra, forçosamente, da de contrato originário: "As formas políticas são apenas a letra (littera) da legislação originária no estado civil e podem, portanto, persistir enquanto um antigo e extenso hábito as considerar necessárias para a maquinaria da constituição política (logo, só subjectivamente). Mas o espírito do contrato originário (anima pacti originarii) implica a obrigação, por parte do poder constituinte, de adequar a forma de governo àquela ideia, portanto, se não o puder fazer de uma vez, a obrigação de a ir mudando, pouco a pouco e de modo incessante, até que, quanto ao seu efeito, concorde com a única constituição legítima, isto é, a de uma república pura; e de as antigas formas empíricas (estatutárias), as quais só serviam para obter a submissão do povo, se dissolverem na originária (racional), que só tem por princípio a liberdade e, inclusive, é a condição de toda a coação necessária para uma constituição jurídica, no sentido genuíno do Estado, e que aí acabará por chegar, também segundo a letra. [...]" (KANT, s./d., p. 156). Em sentido semelhante, na Paz perpétua, lê-se: "Pode-se dizer por consequência que quanto menor é o pessoal do poder do Estado (o número dos dominantes) e maior é por outro lado sua representação, mais a constituição do Estado se acorda com a possibilidade do republicanismo e ela pode esperar elevar-se a ele finalmente por reformas progressivas" (KANT, s./d. b, p. 87-88). Percebe-se, assim, como a ancoragem do direito na ética, em Kant, faz da liberdade política uma tarefa infinita da razão, orientada para os princípios puros do conhecimento prático. 
progressiva entre o concreto e o abstrato, ou mesmo a passagem progressiva de uma dessas esferas à outra, que Schimitt recusa peremptoriamente na concepção de história delineada neste trabalho:

[...] o direito é independente da ética, ele tira sua dignidade de si mesmo, que não provém de sua associação com a ética. Nenhuma relação poderia ser reconhecida entre as condições exteriores e a liberdade interior ou uma passagem progressiva de um à outra. A consequência que resulta do fato de que o direito não pode emanar da ética, Feuerbach a mencionou quando de sua confrontação com Kant. Essa oposição não é o feito de Feuerbach, que exprime claramente a distinção, mas de Kant, que, não apresentando a unidade de maneira bastante distinta, esfuma-a mesmo em muitas oportunidades. [...] (SCHMITT, 2003, p. 68).

Ou ainda, mais claramente, em passagem a propósito de Paul Natorp, mas também, implicitamente, de Kant:

Para Natorp, que não escapou a essa dificuldade, a distinção entre o interno e o externo, que pode ser posta em paralelo com as noções de autonomia e de heteronomia, remete a duas direções diferentes de uma origem legislativa idêntica. O direito vai da heteronomia à autonomia da moral e a moral, da autonomia rumo à heteronomia do direito, como do centro à periferia, enquanto que o direito toma o caminho inverso. Como expresso explicitamente, a heteronomia deve se elevar à autonomia. [...]. Mas a unidade desaparece totalmente, se os pares de opostos interior-exterior, autônomo-heterônomo e mesmo abstrato-concreto são tomados no sentido estrito. Uma elevação da exterioridade rumo à interioridade não pode ser tornada possível por uma passagem progressiva de um ao outro. [...] A majestade ou a superioridade do imperativo categórico reside justamente no fato de que ele conserva sua autoridade sem exceção, independentemente de todas as situações exteriores e do efeito que ele produz sobre os homens. Si fractus illabatur orbis... O papel que cabe às 'condições exteriores da moralidade' numa ética pura é cada vez menos claro (SCHMITT, 2003, p. 109-110). ${ }^{18}$

A separação resoluta entre os reinos do direito e da moralidade conduz Schmitt, como se vê, à recusa de outro aspecto importante de uma filosofia moral erigida a partir do legado de Kant: trata-se de afastar, a qualquer preço, a subordinação do direito à ética, que esse legado filosófico importava, com a sua compreensão do direito como garantidor das "condições exteriores" imprescindíveis à vida ética:

Uma elevação da exterioridade para a interioridade não pode se tornar possível por uma passagem progressiva de um a outro. [...]. Natorp considera que o direito supõe uma harmonia dos objetivos 'de origem exterior', semelhante àquela que exige a moralidade 'de origem interior', uma vez que nos dois casos a mesma coisa é requerida do ponto de vista dos conteúdos. O direito cria as condições exteriores da moralidade interna. Tudo isso significa necessariamente que o direito rege prudentemente a vida do homem e lhe proporciona a segurança necessária para que ele possa realizar projetos mais importantes. O direito não se comportaria de outro modo, em relação à moralidade, que uma dieta apropriada ou um tratamento higiênico, destinado a melhorar as performances que o homem realiza por si mesmo, na plena posse de suas funções corporais (SCHMITT, 2003, p. 109). ${ }^{19}$

18 Cf. ainda, em sentido semelhante, Schmitt (2003, p. 111): “O direito e a moralidade, que Feuerbach e Fichte já haviam distinguido pela razão como dois tipos opostos de julgamentos, não derivam de um princípio idêntico [...]". A separação radical entre direito e moral, embargando qualquer possibilidade de aproximação progressiva dessas duas esferas entre si, importa consequências ainda para o campo da hermenêutica jurídica. Não há mais lugar para uma interpretação da norma positiva que, teleologicamente, tome-a como "tendente" a um sentido de universalidade, tal como avocado por Kant, por exemplo, na Paz perpétua: "A heteronomia não pode em caso algum ser assimilada à autonomia, a exterioridade à interioridade, o nada não pode se elevar ao existente, o concreto não tende ao abstrato. Nenhuma transposição, nenhuma figura de estilo contorna essa incompatibilidade. O indivíduo, ao qual a ética kantiana se dirige, e os múltiplos particulares, desempenhando um papel no direito, não podem se unificar de maneira forçada em um conceito superior. Nem mesmo pela imprecisão de um querer solene ou por uma finalidade vaga, que não existem em nenhuma consciência e que causaram prejuízos ao conjunto da jurisprudência e mais particularmente à hermenêutica jurídica" (SCHMITT, 2003, p. 110-111).

19 Essa articulação entre direito e moral, que torna o primeiro uma espécie de "servo" da segunda, deitaria raízes, indica-nos Schmitt, na Reforma Protestante, como um "prolongamento da oposição entre autoridade espiritual e temporal" (SCHMITT, 2003, p. 109-110), e abriria espaço, esclarece o autor mais adiante, para uma dualidade de poderes incompatível com as teorias medievais da organização do poder, em tudo superiores às modernas. Nesse contexto, logo após uma menção a Lutero e Zuínglio, avança o autor: "[...]. Uma ética que permanece consciente de sua autonomia e se nomeia ciosamente 'pura' deveria portanto deixar o valor ético do indivíduo totalmente independente dos acasos exteriores que podem intervir em sua existência. Ela não pode reconhecer nenhuma contingência que constitua um entrave ao valor moral ou uma incitação ao ser; [...] A majestade ou a superioridade do imperativo categórico reside justamente no fato de que ele conserva a sua autoridade sem exceção, independentemente de todas as situações exteriores e do efeito que ele produz sobre os homens. Si fractus illabatur orbis... O papel que cabe às 'condições exteriores da moralidade' numa ética pura é cada vez menos claro. [...]" (SCHMITT, 2003, p. 109-110). Tal subordinação do direito à ética, que a teoria das "condições exteriores" implica de uma forma ou de outra, representando, ao ver de Schmitt, um desdobramento incoerente de uma ética "pura" baseada na teologia da Reforma, era já denunciada pelo autor na introdução da obra sob análise. Após afirmar, ali, a necessidade 


\section{0 "fosso intransponível" entre o fático e o normativo, e a "decisão soberana"}

Dessa forma, a recusa de toda subordinação do direito à moralidade, tal como expresso pela concepção kantiana, baseia-se na postulação de uma dissociação radical entre esses dois termos. Tal dissociação, por sua vez, funda-se em certas premissas epistemológicas decisivas para os interesses deste artigo, já tangenciadas no curso desta reconstrução. Direito e moralidade, o exterior e o interior, revelam-se, como visto, completamente apartados um do outro, nos termos de um hiato radical entre o concreto e o abstrato, que, segundo o autor, parece afetar a vida moral como um todo e a própria práxis jurídica internamente considerada. Desse ângulo, resta embargada de plano qualquer postulação de uma aproximação paulatina entre a esfera do fato e a da norma, que a ética kantiana, bem como a sua filosofia da história, encaminhava. ${ }^{20}$

A relação entre o fático e o normativo, para Schmitt (2003, p. 119), é de ordem totalmente diversa: "entre o concreto e o abstrato, há um fosso intransponível que não se pode colmatar por uma passagem progressiva de um ao outro".

Fala-se, mais adiante, num "fosso intransponível entre a norma pura e sua execução" (SCHMITT, 2003, p. 122) e, num contexto particular, numa "decisão concreta, determinada mesmo em detrimento da reflexão" (SCHMITT, 2003, p. 121). Postula-se, assim, um hiato "intransponível" entre os níveis do empírico e do ideal, que desacredita qualquer concepção "evolucionista" da história formulada à maneira de Kant. ${ }^{21}$

O movimento do abstrato ao concreto, que se atualiza em diversos níveis da práxis jurídica, é descrito, nesse sentido, em termos absolutamente discricionários: a decisão concreta estabelece com a norma abstrata que Ihe serve de fundamento uma relação de indiferença quanto ao conteúdo:

[...] Assim, é pois necessário que em cada lei positiva esse instante da simples constatação seja valorizado, de acordo com o qual é necessário que sob certas condições algo se comute em uma disposição positiva, seja qual for o seu conteúdo concreto. Essa indiferença em relação ao conteúdo uma ligação pode-se estabelecer assim com o meu estudo Gesetz und Urteil - resulta desse esforço de realização que incumbe ao Estado. A significação dessa indiferença para a decisão judiciária particular é mais evidente e mais esclarecedora, porque aqui a distância entre o julgamento e sua execução não é tão grande. Entretanto, sua significação não é diminuída na determinação da lei positiva. [...] (SCHMITT, 2003, p. 119-120). ${ }^{22}$

de uma separação estrita entre direito e moral, e de fundá-la, ademais, numa oposição radical entre os planos da liberdade exterior e interior, do visível e do invisível, ou do temporal e do eterno, ele asseverava: "[...] Se, segundo a observação de Lutero, os juristas 'não devem se envolver com o reino de Deus', assim os puros éticos devem pelo menos respeitar a autonomia metodológica do reino terrestre" (SCHMITT, 2003, p. 68). Assim, a par da alegada incoerência, apontada acima, o grande problema da subordinação do direito à moral, que toma aquele como garante das "condições exteriores" necessárias à atuação desta, é o fato de desembocar, forçosamente, na virtualidade de uma dualidade de poderes insuportável para a vida estatal: "Ela [a teoria das duas espadas] é a única formulação consequente, resultando da premissa da unidade do direito e da moralidade. A oposição entre o direito e a moralidade não é aquela entre o poder e a norma. O papel da espada - e é aí que reside a notável superioridade metodológica de toda teoria medieval - só poderia ser desempenhado pelo Estado, enquanto poder real. O Estado é por essa razão mais que uma entidade que fixa as 'condições exteriores', uma vez que ele é inteiramente compreendido pelo direito. A desvalorização do direito, que resulta da 'teoria das condições exteriores', nunca poderá ser suficientemente sublinhada" (SCHMITT, 2003, p. 111-112). A argumentação do autor, reivindicando-se medieval em sua fundamentação, talvez o seja, isto sim, na imagem com que se conclui: "Segundo essa concepção [à qual o autor se opõe], o direito se torna uma criada, talvez mesmo uma dona-de-casa ideal que, por sua prudência e seu silêncio, mantém a casa em boa ordem, velando para que todas as condições estejam reunidas para que a atividade profissional de seu marido não seja perturbada" (SCHMITT, 2003, p. 112).

20 Quanto a essa dimensão progressiva, evolutiva, da relação do concreto ao abstrato no pensamento político de Kant, cf. a nota de rodapé $\mathrm{n}^{\circ} 17$. Cf. ainda, nesse contexto, a nota a seguir.

21 Cf., a propósito, nota de rodapé n 17, supra. Enfatizando a relação interna que se estabelece em Kant entre razão prática e filosofia da história, cf. Lebrun (1986, p. 76): "Ora, parece-nos possível mostrar que não existe nenhuma falha entre os opúsculos sobre a História e a análise da razão prática, e até mesmo que é uma exigência inscrita nesta última que leva Kant a conferir cidadania filosófica ao 'sentido da história'. Se assim for, a Weltgeschichte, longe de ser uma noção marginal face à razão prática, contribuiria para garantir a supremacia da razão prática". Articulando em algumas passagens os pensamentos de Kant e Hegel no âmbito da filosofia da história, e discutindo os trabalhos do primeiro mencionados aqui, cf., nesse mesmo ensaio, p. ex., p. 99.

22 Observe-se que, se a equidade em Kant, remetendo ao brocardo do "summum ius, summa iniuria", e importando, em verdade, uma exceção ao sistema de normas gerais, era afastada do âmbito da teoria do direito (KANT, s./d., p. 41), Schmitt, pouco adiante nesse passo, problematizará, citando Hegel, a concepção formalista do direito apresentada por Rudolph Sohm, em passagem do autor que, igualmente, faz referência ao brocardo latino (SCHMITT, 2003, p. 120). Na página seguinte, antes da conclusão do capítulo, Schmitt não deixará de demarcar sua oposição em relação ao autor de Kirchenrecht: "Duas alternativas subsistem, seja reconhecer o ensinamento da Igreja católica como legítimo, seja aceitar o ponto de vista de Lutero, tal qual Sohm e Stutz o apresentaram, e considerar o conjunto do direito como incompatível com a essência da Igreja" (SCHMITT, 2003, p. 121). 
Assim, a passagem da "reflexão jurídica", ou do "direito originário", ${ }^{23}$ à lei positiva deve ser operada pelo Estado "pelo ato de uma decisão soberana". ${ }^{24}$

Ora, inscrevendo a si mesma nesse espaço infinitamente vazio que se estabelece entre a norma abstrata e o caso concreto, e sendo-lhe caracteristicamente indiferente quanto ao conteúdo essa norma superior que lhe dá base, esta "decisão soberana" do ensaio de 1914 não antecipa algo da "decisão autônoma", "indiferente" a quaisquer "substâncias normativas", da Teologia política de 1922 ? ${ }^{25}$

\section{Outros temas relevantes da produção schmittiana posterior discutidos neste ensaio}

Adiantando, assim, certos traços fundamentais da epistemologia jurídica decisionista que será desenvolvida mais tarde, e demarcando-se, pois, do "evolucionismo" que caracteriza a filosofia kantiana da história, a compreensão schmittiana da relação entre norma e fato, nesse ensaio, põe em questão, ainda, outro aspecto saliente da filosofia prática de Kant. Se, na Fundamentação da metafísica dos costumes, relacionou-se o universalismo ético ali propugnado à máxima bíblica do amor ao próximo, que se estende mesmo aos inimigos (KANT, 1980, p. 114), o católico Schmitt afirma a impossibilidade do estabelecimento de uma legislação positiva voltada à concretização desse princípio - nenhuma legislação estatal é capaz de eliminar completamente do mundo humano a tendência à conflitividade, a beligerância, ideia que, a muitos propósitos, antecipa as formulações do Conceito do político (1928) -: “A máxima 'ama teu próximo' não é uma lei positiva e não se o tornará jamais". Assumindo ela, assim, a forma de uma disposição positiva, tem-se que alguns "espíritos [...] veem nesse artigo seu inimigo mortal" (SCHMITT, 2003, p. 121). ${ }^{26}$

Outros motivos importantes ainda, que despontam no ensaio de 1914, parecem antecipar futuros desenvolvimentos da obra schmittiana, inclusive no que respeita à Teologia política. Esse é o caso, por exemplo, de certa tendência de associação do tema do Estado aos níveis do "divino", do "absoluto", que já

23 "O que determina uma proposição jurídica e a distingue, por exemplo, de um regulamento de polícia é que ela se apoia em um elemento do direito originário, não estatal, cuja definição mais precisa não concerne a esta pesquisa [...]" (SCHMITT, 2003, p. 117).

24 "A reflexão jurídica, que serve de linha diretriz à transformação da realidade, deve ser positiva, é dizer que seu conteúdo é fixado pelo ato de uma decisão soberana" (SCHMITT, 2003, p. 119).

25 "A noção de decisão serve assim para estabelecer uma filiação entre Gesetz und Urteil e O valor do Estado e a significação do indivíduo: a justa decisão jurídica constitui, no escrito de 1912, a problemática central, que se afina e se politiza com a aparição do ensaio de 1914. No entanto, a noção de decisão permite igualmente estabelecer continuidades no conjunto da obra schmittiana [...]" (BAUME, 2003, p. 21); "Em O valor do Estado e a significação do indivíduo, são Immanuel Kant e Hans Kelsen [...] que constituem seus referenciais intelectuais, que serão, desde 1922, na Teologia política, eliminados ou violentamente criticados. Todavia, talvez seja preciso nuançar essa transição em seu caráter radical: no ensaio de 1914, Schmitt cede uma parte de autonomia, mesmo que pequena, à esfera estatal, por sua decisão soberana e necessária à execução das normas. Além disso, a atenção teórica muito grande que ele dirige ao conceito de Estado prepara o caminho a uma forma de estatismo, que se exprimirá desde 1921, com a aparição de A Ditadura" (BAUME, 2003, p. 51). No mais, quanto a essa reflexão sobre o papel de realização do direito que incumbe ao Estado, em seu aspecto francamente decisionístico, prefigura ela, ainda, uma discussão que despontará no estudo Ditadura, de 1921, e que será, futuramente, objeto de uma problematização aguda por parte de Benjamin. Trata-se do problema da contradição entre norma jurídica e norma de realização do direito, que atravessaria a práxis jurídica em todos os níveis, e que o fenômeno da ditadura evidencia: "[...] [A ditadura] Pressupõe, por isso, que o adversário não se atém às normas jurídicas que o ditador reconhece como o fundamento jurídico que dá a medida de sua ação. Como o fundamento jurídico, mas, naturalmente, não como o meio técnico objetivo de sua ação. A oposição entre norma jurídica e norma de realização do direito, que atravessa todo o direito, se converte aqui em uma oposicão entre norma jurídica e regra técnico objetiva da ação. [...]" (SCHMITT, 2009, p. 181). Cf. ainda, quanto a essa problemática, Schmitt (2009, p. 26 e 30$)$. De resto, quanto a essa articulação entre Gesetz und Urteil, de 1912, e o ensaio sobre O valor do Estado, apontada pelo próprio Schmitt, e fundada no problema da decisão, ela, sem dúvida, procede. O conceito de "decisão correta" ocupava ali, é certo, um lugar central. Também ali a temática da realização do direito não se deixava esgotar no problema da norma. "Nos casos em que o conteúdo da decisão, e as motivações disso, passam ao segundo plano em relação à necessidade de chegar de qualquer modo a uma decisão, vale dizer naqueles casos em que o conteúdo da decisão resulta relativamente indiferente [...]". Tinha-se, a bem dizer, que essa relativa indiferença ao conteúdo assistiria a toda decisão: "[...] tendo-se conta do elemento de indiferença conteudística que caracteriza toda decisão" (SCHMITT, 2016, p. 137-138). Contudo o vínculo essencial que se estabelecia ali, por exemplo, entre a noção de "decisão correta" e as de "previsibilidade" ou "calculabilidade", extraídas da observação da práxis jurídica, parece impedir uma associação mais precisa entre o argumento dessa obra e a epistemologia decisionista elaborada anos depois: "Uma decisão judiciária é portanto correta quando se mostra previsível e calculável. Isso é o que deriva do postulado da determinidade jurídica e da observação da práxis judicial" (SCHMITT, 2016, p. 141).

26 À fissura intransponível que se estabelece entre o plano da ideia e aquele do concreto corresponde, a bem ver, uma impossibilidade crônica de superação da beligerância que caracterizaria a condição humana, e, pois, de concretização, mesmo tendencial, de uma legalidade universal vertida à paz perpétua: "A renúncia à justiça intemporal e a indiferença, quanto ao conteúdo, são a consequência da encarnação do direito, o sacrifício que deve ser consentido, porque se é submetido aos poderes do mundo dos fenômenos reais. A máxima 'ama teu próximo' não é uma lei positiva e não se o tornará jamais. Se homens corajosos e virtuosos chegam, em circunstâncias particulares, a fazer dela o ponto de referência de uma legislação estatal, essa máxima se comuta em um artigo, ela entra em uma outra esfera. A impressão que ela produz sobre os espíritos, que veem nesse artigo seu inimigo mortal, é completamente outra" (SCHMITT, 2003, p. 121). 
aqui se insinua, e que, a partir de outro prisma metodológico, é verdade, reaparecerá no ensaio de $1922 .{ }^{27} \dot{E}$ o caso, igualmente, do recurso a certa "antropologia negativa", a qual, nessa obra, relaciona-se intimamente ao problema daquele hiato epistemológico que, segundo exposto acima, separa radicalmente os níveis do abstrato e do concreto, os planos do ideal e do fático, conduzindo à necessidade de uma "decisão soberana", ilimitada do ponto de vista de seu conteúdo.$^{28}$ É ainda, por fim, o caso da proposição de paralelismos entre a estrutura institucional da Igreja Católica e aquela do Estado moderno ${ }^{29}$ procedimento retomado mais tarde, particularmente em Catolicismo romano e forma política, ${ }^{30}$ e que já se relaciona, como visto, à discussão de certa dimensão decisionística, que ressalta tanto na decisão da autoridade eclesiástica como naquela da autoridade temporal.

Diante de tantas temáticas que, mais tarde, reaparecerão na rica produção teórica de Schmitt, e que despontam, de forma original e internamente articulada, no ensaio de 1914, é de se perguntar por que o debate em torno de sua obra parece atribuir uma importância relativamente pequena à primeira incursão mais detida do autor no campo da filosofia política. É possível, aliás, ante a revalorização da obra de Schmitt, que se vem assistindo nos últimos anos, que tal negligência venha a ser reparada em breve. Um dos motivos que poderia talvez explicá-la é o fato de que, nesse trabalho de juventude, todas essas temáticas que, mais tarde, se organizarão no seio de uma epistemologia jurídica de tipo decisionista, e que, ali, darão expressão a essa nova orientação metodológica, permanecem ainda envoltas em uma "couraça metodológica" insólita para o leitor atraído pela obra schmittiana dos anos 20 em diante, dizente com um normativismo peculiar, de que se falou acima, que se articula, por sua vez, a um jusnaturalismo sui generis. ${ }^{31}$

27 "O conceito de Estado recebe assim, em relação ao direito, uma posição estritamente análoga àquela que o conceito de Deus - que resulta da necessidade de realizar a moral no mondo real - recebe em relação à ética" (SCHMITT, 2003, p. 102). Quanto à "tendência" da Teologia política "ao absoluto", indica-se Ari Marcelo Solon (1997, p. 87).

28 "[...]. Essa perspectiva anti-individualista, assim como uma antropologia negativa permanecerão duravelmente inscritas na obra de Carl Schmitt, bem como sua sustentação teórica de um Estado forte. [...]" (BAUME, 2003, p. 50). Cf. ainda a esse respeito, em Schmitt (2003, p. 121). Em passagem em que se apresenta a Igreja Católica, o seu ensinamento, como exemplo em vista não apenas da "[...] necessidade de uma decisão concreta, determinada mesmo em detrimento da reflexão", mas também de uma "aspiração a uma instância certa e infalível que apresente essa formulação", avança o autor: "Com efeito, se se consideram os homens em sua corporeidade, deve-se igualmente considerar esses fracos que devem e querem saber em que referenciar-se. Se eles são submetidos a um superior, oriundo do mundo material, as ordens deste têm então a mesma materialidade concreta. Este último executa a lei que é o fundamento mesmo de sua existência. A consequência que resulta da infalibilidade das decisões ex cathedra é evidente [...]" (grifo meu). Como sugere a passagem acima, uma desconfiança extrema nas faculdades morais do homem, em sua capacidade de aceder aos princípios eternos de verdade e justiça - que parece ecoar uma certa tradição agostiniana, muito mais que Kant ou Platão - acompanha-se da postulação de uma instância decisória incontrastável por parte de seus destinatários, "esses fracos que devem e querem saber em que referenciar-se". Esteja-se diante da Igreja romana ou do Estado moderno, o "fosso intransponível", para todo homem concreto, entre o caso particular e a norma abstrata, torna simplesmente carente de fundamento qualquer possibilidade de crítica do poder e da autoridade existentes de fato. Vai na mesma linha o descrédito em relação às diferentes formas de moderação e limitação do poder estatal propostas ao longo da história da filosofia, as quais, desconfiando da "maldade" ou da "fraqueza" que, no homem, afastam-no de uma sua determinação pela razão, pensam poder remediá-lo pela implementação de determinados mecanismos institucionais: "Seja como for, o receio de um emprego abusivo do poder factual do Estado reside numa desconfiança em relação à maldade, à fraqueza dos homens ou em relação à sua propensão a tornar-se-o. O erro metodológico é sempre o mesmo. Nenhuma lei pode executar-se por si mesma, só os homens podem ser os guardiões das leis, e para aquele que não se fia nos guardiões de nada serve dar-lhe novos. O fosso intransponível entre a norma pura e a sua execução não pode ser preenchido por uma grande quantidade de intermediários" (SCHMITT, 2003, p. 122). De resto, quanto à dimensão "anti-individualista" do ensaio schmittiano, a que se aludiu acima, e que constitui, certamente, um dos aspectos salientes dessa obra, mas que escapa aos interesses prioritários do presente artigo, apontou-a Ronaldo Porto Macedo Jr. (2001, p. 22)

Cf. a nota de rodapé anterior.

30 "[...] em O valor do Estado e a significação do indivíduo se inscrevem as problemáticas da legitimidade parlamentar, desenvolvida em Parlamentarismo e democracia e aquela da confrontação 'teórica' das instituições do Estado e da Igreja, prolongada em Römischer Katholizismus und politische Form (1923)" (BAUME, 2003, p. 23).

${ }_{31}$ "Para retomar uma expressão de Santo Agostinho, o direito é para o Estado: origo, informatio, beatitudo. Em consequência, não há outro Estado senão o Estado de direito e cada Estado empírico recebe sua legitimação de seu papel de primeiro servidor do direito. [...]" (SCHMITT, 2003, p. 101). Quanto a esse direito originário, não estatal, afirma-se em outro passo: "O que determina uma proposição jurídica e a distingue, por exemplo, de um regulamento de polícia é que ela se apoia em um elemento do direito originário, não estatal, cuja definição mais precisa não concerne a esta pesquisa, mas do qual se pode dizer (para se expor ao risco do paradoxo) que é um direito natural sem que o naturalismo possa penetrá-lo" (SCHMITT, 2003, p. 117). Não existe, nesse sentido, qualquer possibilidade de uma aproximação progressiva das instituições do mundo sensível à perfeição do mundo inteligível: um fosso intransponível se estabelece entre esses planos, abrindo espaço, por sua vez, para uma decisão de autoridade virtualmente incondicionada do ponto de vista de seu conteúdo. Mesmo assim, e independentemente do conteúdo dessa decisão que positiva a norma abstrata, o direito estatal, positivo, continua a espelhar, forçosamente, mesmo que de forma muito difusa, aquelas formas eternas que, nesse sentido, subjazem-Ihe necessariamente: "Uma vez que o Estado estabelece uma ligação entre o direito e o mundo real, um fator empírico desliza, por meio do Estado, para dentro da norma jurídica proclamada pela esfera estatal. Essa norma passa como um mediato através do Estado e sofre assim uma modificação específica. Todo o domínio do direito empírico se divide assim em dois complexos. [...]. A norma extra-empírica, em sua definição, não conhece a sujeição. A propensão à constrição é um elemento que é introduzido no direito pelo Estado". O dualismo que caracterizaria, portanto, o campo jurídico é então apresentado nos seguintes termos: "Portanto, de uma parte, há o direito que precede o Estado e que é, em seu princípio, independente dele. Em sua relação com o Estado, o direito pode ser caracterizado como dominante, originário e ser considerado como abstrato em sua relação com as expressões concretas da vontade, que correspondem a seu reflexo no mundo empírico. De outra parte, há o direito estatal que, como um servidor, é destinado a fins determinados, tal um direito mediador que não estabelece relações de meio e de fim com o direito originário. Sua finalidade resulta mais de sua percepção do mundo empírico como campo de atividade. Essa oposição entre esses dois tipos de direitos não revela porém duas massas fechadas, distintas do ponto de vista do conteúdo de seu regulamento. É no interior de cada proposição jurídica empírica particular que uma separação deve efetuar-se. O que determina uma proposição jurídica e a distingue, por exemplo, de um regulamento de polícia é que ela se apoia em um elemento do direito originário, não estatal, cuja definição mais precisa não concerne a esta pesquisa, mas do qual se pode dizer (para se expor ao risco do paradoxo) que é um direito natural sem que o naturalismo possa penetrá-lo" (SCHMITT, 2003, p. 117). Nesse sentido, no que respeita às normas penais, por exemplo, se as condutas ali prescritas parecem repousar, em última análise, nesse direito originário e pré-estatal, "a indicação da pena e sua gravidade pertence a esse complexo que não é afetado pela norma pura" (SCHMITT, 2003, p. 118). A ideia é ainda precisada na sequência (p. 118-120). 


\section{Conclusões}

A reconstrução de alguns dos motivos centrais desenvolvidos no ensaio $O$ valor do Estado e a significação do indivíduo, a que se procedeu aqui, permite-nos, agora, assentar as seguintes conclusões:

1) Fica evidente a importância dessa obra no quadro dos debates em torno da obra de Carl Schmitt. Temas fundamentais no percurso intelectual do autor, como os de uma decisão soberana, ilimitada do ponto de vista normativo; o problema da inimizade e da beligerância inscritos na condição humana; uma apreciação teórica do Estado e do político fundada em motivos teológicos, que se voltam ao nível do absoluto; a dimensão "anti-individualista" desse pensamento, articulada a certa "antropologia negativa", que mais tarde se socorrerá de Hobbes; a questão dos paralelismos estruturais entre a Igreja romana e o Estado moderno etc., todos esses temas, se não desenvolvidos, ao menos prefigurados nesse ensaio de 1914, no qual muitos deles, pelo menos, despontam pela primeira vez, e em cujo seio se articulam, condicionando-se reciprocamente, deveriam ter-lhe carreado, até o momento, uma atenção maior de nossa parte, da literatura voltada a Schmitt de maneira geral. ${ }^{32}$

2) Se é verdade que a preocupação schmittiana com o problema da decisão é anterior ao ensaio de $1914,{ }^{33}$ pela primeira vez ela desponta, aqui, como o problema de uma decisão soberana, completamente indiferente a critérios normativos, ou mesmo sociológicos, estruturais, exteriores a si, pelo menos do ponto de vista do seu conteúdo. Trata-se de uma problemática central para a produção schmittiana posterior, dizente com o núcleo do seu pensamento durante o período de Weimar, no mínimo, que essa obra de 1914, em certos aspectos precoce, antecipa - sugerindo, vivamente, a presença marcante da problemática decisionista, pelo menos em germe, nas reflexões do jovem Carl Schmitt anteriores a $1914 .{ }^{34}$

3) Ressalte-se, ainda, na esteira de outros comentadores, a influência que, do ponto de vista metodológico, o legado de Kant e o pensamento neokantiano exercem sobre esse livro. É o que se evidencia em suas teses sobre a prevalência, epistemológica, da norma sobre o fato, do direito sobre o Estado etc. Esse dispositivo conceitual tipicamente normativista, porém, não deveria encobrir o outro lado do problema: se se encontram nesse ensaio, pelo menos prefigurados, motivos mais tarde desenvolvidos em termos de uma epistemologia jurídica decisionista, também é verdade que, nessa obra, esses motivos são trabalhados, em grande medida, justamente em polêmica com os neokantianos, senão com o próprio Kant - conforme sugere, por exemplo, a passagem sobre o imperativo categórico e o Si fractus illabatur orbis..., discutida acima.

O "fosso intransponível" entre o concreto e o abstrato alveja não apenas as construções de Natorp ou Cohen, mas, fundamentalmente, o núcleo da própria argumentação kantiana em moral, em direito e no campo da filosofia da história - em todos esses níveis, de uma maneira ou de outra, tratava-se, para Kant, de encaminhar uma aproximação progressiva, mesmo infinita, do plano do concreto ao do abstrato, no seio de uma típica filosofia do progresso. Por esses motivos, não me parece exagerado afirmar que, para os germens da problemática decisionista que essa obra encerra, a recusa das epistemologias normativistas de marca kantiana constitui uma determinação fundamental. ${ }^{35}$

\footnotetext{
A primeira tradução do livro, por exemplo, data de 2003. Trata-se, justamente, da edição utilizada neste artigo.

Cf. o que se comenta a respeito de Lei e julgamento (Gesetz und Urteil) na nota de rodapé $n^{\circ} 25$.

A redação do livro seria de 1913. Cf. Baume (2003, p. 9).

Não por acaso, em trabalhos importantes de Schmitt dos anos 20 em que a problemática decisionista é elaborada, as menções à filosofia jurídica de Kant tomam-na, via de regra, como antítese dos princípios metodológicos ali desenvolvidos. Assim, por exemplo, na Teologia política. A cientificidade jurídica que esse trabalho estabelece, a partir da oposição polar entre "norma" e "decisão", e que define a soberania, atrelada que se encontra ao conceito de estado de exceção, no âmbito de uma decisão extrema, completamente desembaraçada da esfera da norma - justamente, a decisão sobre a exceção -, só podia ver no normativismo kantiano, radicalmente infenso à possibilidade da exceção, o seu antípoda: "[...] A viva consciência da importância do caso excepcional dominante no direito natural do século XVII, logo se perde no século XVIII quando foi criada uma ordem relativamente duradoura. Para Kant, o direito de necessidade não é, de forma alguma, direito. [...]. Fica claro que um neokantiano, como Kelsen, não sabe, sistematicamente, o que fazer com o estado de exceção" (SCHMITT, 2006, p. 15). A decisão sobre a exceção, em sua concretude radical, dizendo do cerne das preocupações metodológicas de Schmitt, escapa totalmente à esfera de uma norma pura, e, assim, à tradição jusfilosófica que remonta a Kant: "Ela [a forma jurídica] não tem o vazio apriorístico da forma transcendental, pois ela surge, justamente, do aspecto juridicamente concreto" (SCHMITT, 2006, p. 32).
} 
4) Em sua própria época, o jovem Carl Schmitt não hesitou em desafiar certos cânones acadêmicos, trazendo à tona a perplexidade que o problema da decisão, potencialmente, encerra: entre a norma abstrata e a sua realização concreta, infinitas são as possibilidades de sua atualização à disposição do intérprete. Mesmo a ideia de uma "moldura legal" solidamente estabelecida sucumbe diante dessa apresentação da "decisão soberana", indiferente a quaisquer limitações de tipo normativo, no que respeita ao seu conteúdo. ${ }^{36}$ A discricionariedade, virtualmente infinita, na passagem do abstrato ao concreto inviabiliza o tomar-se a reflexão jurídica, o conceito que ela determina, uma ideia reguladora.

E quanto a nós? Em uma época como a nossa, que tem depositado, visivelmente, tanta confiança nos conceitos de justiça, estado de direito e democracia, tomados, todos eles, como ideias reguladoras, em cuja direção caminhamos - satisfeitos - indefinidamente, estaríamos dispostos a atualizar e aprofundar uma tal reflexão sobre o problema da decisão? Talvez aí se encontrem algumas pistas para entender os obstáculos em que tem esbarrado, inadvertidamente, essa caminhada triunfal "para o melhor", conforme a expressão do Professor Pangloss. Para essa tarefa, apesar das tristes escolhas políticas que realizou, notadamente a partir dos anos 20 , o pensamento de Schmitt, desde a década anterior, como se viu aqui, deve representar, metodologicamente, um subsídio importante. E, da mesma forma, o pensamento do jovem Benjamin, naquilo para o qual se voltou, não tanto ao tema da decisão, mas ao da "indecidibilidade" num horizonte jurídico. ${ }^{37} \mathrm{O}$ diálogo crítico entre os dois move-se, justamente, no interior do terreno onde é preciso manobrar: o espaço - infinitamente vazio - entre as regras e a sua concretização na realidade.

\section{Referências}

Andrade, Walter. Liberdade ou estado de exceção? O direito em Kant, Schmitt e Benjamin. Tese (Doutorado em Filosofia e Teoria Geral do Direito) - Faculdade de Direito, Universidade de São Paulo, São Paulo, 2017.

Baume, Sandrine. Carl Schmitt, penseur de l'État. In: Schmitt, Carl. La valeur de l'État et la signification de l'individu. Tradução, introdução e notas: Sandrine Baume. Genève: Droz, 2003. p. 1055.

Bendersky, Joseph W. "Schmitt's diaries". In: Meierhenrich, Jens; Simons, Oliver. The Oxford Handbook of Carl Schmitt. New York: Oxford University Press, 2016. p. 117-146.

Bercovici, Gilberto. Entre institucionalismo e decisionismo. Novos Estudos, Cebrap, São Paulo, n. 62, p. 191-193, mar. 2002.

Freund, Julien. Vue d'ensemble sur l'oeuvre de Carl Schmitt. Revue européenne des sciences sociales, Genève, t. 16, n. 44, p. 7-38, 1978. Miroir de Carl Schmitt.

Habermas, Jürgen. Beetween facts and norms: contributions to a discourse theory of law and democracy. Tradução: William Rehg. Cambridge, UK; Malden, USA: Polity Press, 1997.

Kant, Immanuel. Fundamentação da metafísica dos costumes. Tradução: Paulo Quintela. São Paulo: Abril, 1980.

Kant, Immanuel. Metafísica dos costumes, parte I: princípios metafísicos da doutrina do direito. Tradução: Artur Morão. Lisboa: Edições 70, [2007?].

Kant, Immanuel. Vers la paix perpétuelle. In: Vers la paix perpétuelle, Que signifie s'orienter dans la pensée?, Qu'est-ce que les lumières? et autres textes. Tradução: Jean-François Poirier e Françoise Proust. Paris: GF-Flammarion, 2006.

\footnotetext{
36 Mas não foi essa, também, a conclusão de Kelsen, a quem Schmitt atribuiria, mais tarde, um "decisionismo degenerado" (SCHMITT, 2006, p. 4-5) no capítulo final da Teoria pura do direito? "A propósito, importa notar que, pela via da interpretação autêntica, quer dizer, da interpretação de uma norma pelo órgão jurídico que a tem de aplicar, não somente se realiza uma das possibilidades reveladas pela interpretação cognoscitiva da mesma norma, como também se pode produzir uma norma que se situe completamente fora da moldura que a norma a aplicar representa" (KELSEN, 1984, p. 471)

37 Cf. nota de rodapé $n^{\circ} 4$.
} 
Kelsen, Hans. Teoria pura do direito. Tradução: João Baptista Machado. 6. ed. Coimbra: Arménio Amado, 1984.

KervÉgan, Jean-François. Hegel, Carl Schmitt: le politique entre spéculation et positivité. Paris: PUF, 1992.

Lebrun, Gérard. Uma escatologia para a moral. In: Kant, Immanuel. Ideia de uma história universal de um ponto de vista cosmopolita. Tradução: Rodrigo Naves e Ricardo Terra. São Paulo: Brasiliense, 1986. p. $75-101$.

Macedo JR., Ronaldo Porto. Carl Schmitt e a fundamentação do Direito: a formação do decisionismo institucionalista Schmittiano entre os anos 1920 e 1940. São Paulo: Max Limonad, 2001.

Paulson, Stanley L. Hans Kelsen and Carl Schmitt: growing discord, culminating in the "Guardian" controversy of 1931. In: Meierhenrich, Jens; Simons, Oliver. The Oxford Handbook of Carl Schmitt. New York: Oxford University Press, 2016. p. 510-546.

Schmitt, Carl. La dictadura: desde los comienzos del pensamiento moderno de la soberanía hasta la lucha de classes proletaria. Tradução: José Díaz García. Madrid: Alianza, 2009.

Schmitt, Carl. La valeur de l'État et la signification de l'individu. Tradução, introdução e notas: Sandrine Baume. Genève: Droz, 2003.

Schmitt, Carl. Legge e giudizio: uno studio sul problema della prassi giudiziale. Tradução: Emanuele Castrucci. Milano: Giuffrè, 2016.

Schmitt, Carl. Teologia política. Tradução: Elisete Antoniuk. Belo Horizonte: Del Rey, 2006.

Solon, Ari Marcelo. Teoria da soberania como problema da norma jurídica e da decisão. Porto Alegre: Fabris, 1997.

Recebido em: 30/04/2019

Aprovado em: 08/07/2019 